\title{
SURGERY VERSUS ENDOSCOPIC THERAPIES FOR EARLY CANCER AND HIGH-GRADE DYSPLASIA IN THE ESOPHAGUS: a systematic review
}

\author{
Fabio Alberto Castillo BUSTAMANTE¹, Eduardo Guimarães HOURNEAUX DE MOURA', \\ Wanderley BERNARDO², Rubens Antonio Aissar SALLUM ${ }^{3}$, Edson IDE ${ }^{1}$ and Elisa BABA ${ }^{1}$
}

Received 17/8/2015

Accepted 19/9/2015

\begin{abstract}
Background - Esophageal cancer occurs as a local disease in $22 \%$ of cases, and a minority of this disease is limited to the mucosa or submucosa (early lesions). Endoscopic mucosal resection, endoscopic submucosal dissection, photodynamic therapy, laser therapy, and argon plasma coagulation have emerged as alternatives to surgical resection for early lesions. Objective - The aim of this systematic review is to identify studies that statistically compare survival, disease-free survival, morbidity and mortality associated with the procedure, and mortality associated with cancer in the endoscopic versus surgical therapies. Data sources - A systematic review using MEDLINE, COCHRANE, EMBASE, EBSCO, LILACS, Library University of Sao Paulo, BVS, and SCOPE. Study selection - Randomized controlled trial, controlled clinical trial, clinical trial, and cohort study Criteria - Studies that statistically compare survival, disease-free survival, morbidity and mortality associated with the procedure, and mortality associated with cancer in patients who underwent endoscopic and surgical therapy for early lesions of esophageal cancer. Data extraction - Independent extraction of the articles by two authors using predefined data fields, including study quality indicators. Limitation - Only retrosprospective cohort studies comparing the endoscopic and surgical therapies were recovered. Results - The survival rates after 3 and 5 years were different and exhibited superiority with the surgical therapies over time. Endoscopy is superior in the control of mortality related to cancer with a high rate of disease recurrence. With regard to the comorbidity and the mortality associated with the procedure, endoscopy is superior. Conclusion - There is no evidence from clinical trials. In this systematic review, surgical therapies showed superiority for survival, and endoscopic therapies showed superiority in the control of mortality related to cancer with a high rate of disease recurrence; also, for the comorbidity and the mortality associated with the procedure, endoscopy is superior. Prospective, controlled trials with large sample sizes are necessary to confirm the results of the current analysis.
\end{abstract}

HEADINGS - Esophageal neoplasms, surgery. Gastrointestinal endoscopy. Morbidity. Review.

\section{INTRODUCTION}

The prevalence of early cancers (invading no deeper than the submucosa) has increased, especially in Asian countries, where upper digestive screening is common $^{(14,31)}$. Similarly, in the United States, there has been an increased diagnosis of early lesions starting in the Barrett's esophagus ${ }^{(1,16,29)}$.

Disease confined to the esophagus or local disease is present in $22 \%$ of the cases, and a minority of the patients have disease that is limited to the mucosa or submucosa (T1N0M0). An esophagectomy is the first line of therapy for patients with stage T1N0M0. For patients with a localized and potentially resectable form of the disease, the median survival strongly correlates with disease stage, which is where the goal of surgery is the curative resection $\mathrm{R} 0^{(2,5,14,31)}$. Advanced age and comorbidities increase the risk of postoperative cardiorespiratory complications, anastomotic leakage, reoperation rates, wound infection, and death ${ }^{(15)}$. Endoscopic resection (ER) is an alternative to surgical resection of the mucosal and submucosal neoplastic lesions and has the benefit of not having major surgical complications. Endoscopic mucosal resection (EMR), endoscopic submucosal dissection (ESD), photodynamic therapy (PDT), laser therapy, and argon plasma coagulation (APC) have been developed as alternatives to surgical resection for early lesions. The benefit of these therapies is obvious and has been supported by multiple case study publications, as well as systematic reviews, with no statistical data analysis. Therefore, the benefits of these therapies compared with surgery are still not clear ${ }^{(3,4,11,17,27)}$.

\section{OBJECTIVES}

The aim of this systematic review is to identify studies that statistically compare survival, disease-free survival, morbidity and mortality associated with the procedure, and mortality associated with cancer, in the endoscopic versus surgical therapies.

Declared conflict of interest of all authors: none

Disclosure of funding: no funding received

${ }^{1}$ Serviço de Endoscopia Gastrointestinal, Departamento de Gastroenterologia, Hospital das Clínicas, Faculdade de Medicina Universidade de São Paulo, São Paulo, SP, Brasil; ${ }^{2}$ Projeto Diretrizes, Associação Médica Brasileira, São Paulo, SP, Brasil; ${ }^{3}$ Divisão de Cirurgia Esofágica, Departamento de Gastroenterologia, Hospital das Clinicas Universidade de São Paulo, São Paulo, SP, Brasil.

Correspondence: Fabio Alberto Castillo Bustamante. Serviço de Endoscopia Gastrointestinal, Departamento de Gastroenterologia, Hospital das Clinicas, Faculdade de Medicina, Universidade de São Paulo (FM-USP). Av. Dr. Enéas de Carvalho Aguiar, 255, 6ªndar, Bloco 3 - CEP: 05403-000 - São Paulo, SP, Brasil. E-mail: facastillobu@gmail.com 


\section{METHODS}

\section{PROSPERO 2014: CRD42014013170 (33).}

\section{Eligibility criteria}

Types of studies: (Randomized Controlled Trial, Controlled Clinical Trial, Comparative Study).

Types of participants: Early esophageal cancers that are classified as Tis (high-grade dysplasia, which includes all noninvasive neoplastic epithelial that was formerly called carcinoma in situ) and T1 tumours, which are split into T1a and T1b subcategories depending on the depth of the invasion $^{(9)}$.

- M1 - Limited to the epithelial layer

- M2 - Invades the lamina propria

- M3 - Invades into but not through the muscularis mucosa

M1 tumours correspond to the Tis stage in the AJCC stage definition, while both M2 and M3 tumours would be considered T1a lesions.

Tumours invading the submucosa are subclassified as follows ${ }^{(28)}$ :

- SM1 - Penetrates the shallowest one-third of the submucosa

- SM2 - Penetrates into the intermediate one-third of the submucosa

- SM3 - Penetrates the deepest one-third of the submucosa

All of these subcategories would be considered $\mathrm{T} 1 \mathrm{~b}$ disease according to the AJCC stage definitions ${ }^{(8)}$. Early esophageal cancer is considered to be T1b SM1 (200 $\mu$ invasion to the submucosa).

Types of intervention: esophagectomy or any approach compared with endoscopic mucosal resection (EMR), endoscopic submucosal dissection (ESD), photodynamic therapy (PDT), laser therapy, and argon plasma coagulation (APC).

Types of outcome measures: statistically compare survival, disease-free survival, the complications associated with the procedure (morbidity and mortality), and the mortality associated with cancer.

In this search, we do not limit ourselves by year of publication or by language.

\section{Search MEDLINE}

P: (Esophageal Neoplasms OR Esophageal Neoplasm OR Neoplasm Esophageal OR Middle third submucosal layer OR Deep third submucosal layer OR Submucosal esophageal cancer AND ESOPHAG*) AND I: (Surgical Procedures, Operative OR OREsophagectomy OR Esophagectomies) AND C: (Endoscopy OR Surgical Procedures, Endoscopic OR Gastrointestinal Surgery, Endoscopic OR Esophagogastroduodenoscopies).

EBSCO, EMBASE, LILACS, COCHRANE, LIBRARY UNIVERSITY OF SAO PAULO, BVS, SCOPE

P: Esophagus cancer AND early AND I: surgery AND C: endoscopy.

\section{Study selection}

Two reviewers performed the eligibility assessment, which was performed independently in an unblinded standardized manner. Each reviewer completed a thorough reading of the abstract to identify studies comparing endoscopic with surgical techniques. The studies that were selected were read in their entirety and were excluded according with criteria from JADAD ${ }^{(13)}$ NEWCASTLE OTTAWA $^{(10)}$ and Methodology Check List SIGN ${ }^{(26)}$. We excluded studies that did not report the results in absolute numbers. Disagreements between reviewers were resolved by consensus.

\section{Data collection process}

We extracted the data through a detailed reading of the results of each study, including the information on mortality at 3 and 5 years, disease-free survival at 5 years, complications associated with the procedure (mortality and morbidity), and mortality associated with cancer. We only included the absolute numbers reported in the text of the article or with the analysis of the graphs. We excluded an article for not reporting the results in absolute numbers. One review author extracted the data described below from the included studies, and the second author checked the extracted data. Disagreements were resolved by discussion between the two review authors; we did not contact authors for further information.

\section{Data items}

We select items from populations with early adenocarcinoma or squamous cell cancer of the esophagus (EAC ESCC), and we understood these cancers as mucosal and submucosal M1, M2, M3, SM1, SM2, and SM3.

We compared endoscopic submucosal dissection, endoscopic mucosal resection, photodynamic therapy, and ablative therapies (EMR, ESD, PDT, TA) with esophagectomies by a transhiatal or a transthoracic approach and minimally invasive techniques (TH, TT, MI).

\section{Risk of bias in the individual studies}

The first approach to identify the risk of bias was undertaken using the NEWCASTLE OTTAWA (11) and Methodology Check List: Cohort studies SIGN ${ }^{(26)}$.

\section{Synthesis of results}

We performed an analysis with the available software RevMan $5^{(7)}$ using the following characteristics: dichotomous data type, statistical method of Mantel-Haenszel, fixed effect model analysis, effect measure risk difference, study confidence interval $95 \%$, total confidence interval $95 \%$, and organized by year of study.

\section{Risk of bias across the studies}

To identify true heterogeneity and cause for publication bias between studies, we conducted both a graphic funnel plot and an $\mathrm{I}^{2}$ analysis. We noted that a value of $\mathrm{I}^{2}$ greater than $50 \%$ was considered as high heterogeneity, and if the study was outside of the funnel plot it was regarded as a publication bias, but if it was inside the funnel plot, it was considered to be true heterogeneity. 


\section{RESULTS}

\section{Study selections}

We identified 9859 studies through the PUBMED search and through the COCHRANE, EMBASE, EBSCO, LILACS, Library University of Sao Paulo, BVS and SCOPE we found 9527 studies. After eliminating the repeat studies, we identified a total of 16699 studies. We excluded studies that did not have information concerning early esophagus cancer. NO PROSPECTIVE CLINICAL TRIAL WAS FOUND. We chose 20 studies that we reviewed with the NEWCASTLE OTTAWA and the Methodology Check List: Cohort studies SIGN and excluded 7 of these studies. We included 13 studies for the qualitative analysis and 12 studies for the quantitative analysis (Figure 1).

\section{Study characteristics}

The characteristics of the studies are summarized in Table 1 and describe the oncologic diagnosis analysed. The number of interventions for each treatment group and the report in absolute numbers gives each outcome of interest extracted.

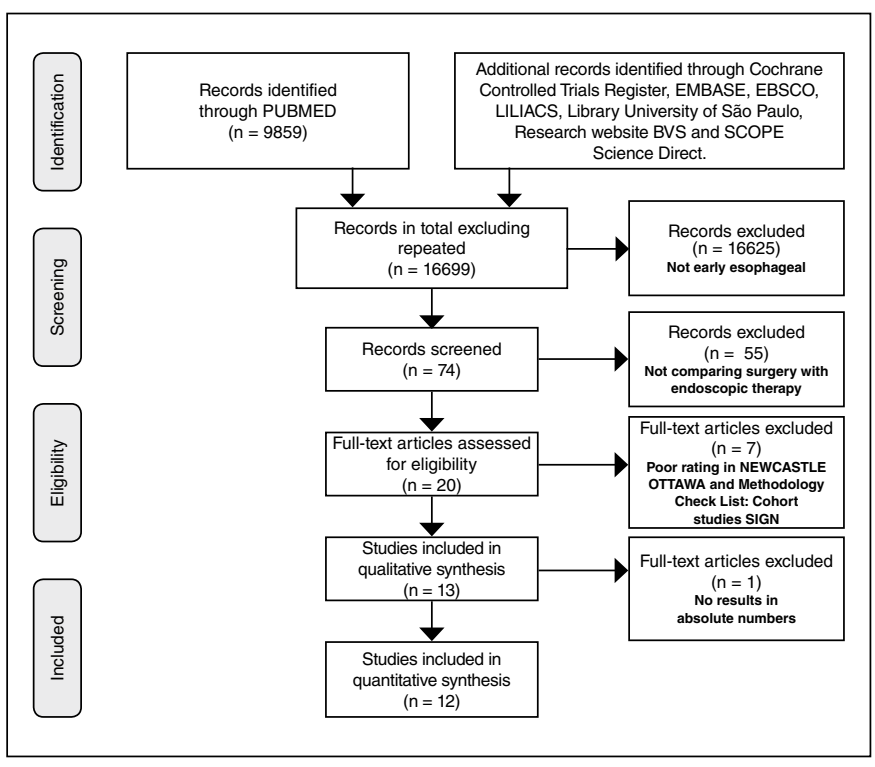

FIGURE 1. Flow diagram studies selection ${ }^{(19)}$

TABLE 1. Study characteristics

\begin{tabular}{|c|c|c|c|c|c|c|}
\hline Study & Population & Intervention & $\begin{array}{c}\text { MAP* } \\
(\text { MoAP)* }\end{array}$ & $\begin{array}{c}\text { Survival 3 } \\
\text { year (MAC)* }\end{array}$ & $\begin{array}{c}\text { Survival } 5 \text { year } \\
\text { (MAC)* }\end{array}$ & DFS $^{*}$ \\
\hline \multirow[t]{2}{*}{ Merkow RP, $2014^{(18)}$} & $\begin{array}{c}\text { M1-2-3 } \\
\text { SM1-2-3 }\end{array}$ & E 1428 (EMR ESD TA) & 7 & & 1092 & \\
\hline & EAC ESCC $04-10$ & S $3962(\mathrm{NS}) *$ & 139 & & 3470 & \\
\hline \multirow{2}{*}{ Wani S, $2014^{(32)}$} & $\begin{array}{l}\text { M1-2-3 } \\
\text { SM1-2-3 }\end{array}$ & E 430 (NS)* & & 318 & 266 & \\
\hline & EAC ESCC $98-09$ & S $1586(\mathrm{NS}) *$ & & 1237 & 1110 & \\
\hline \multirow{2}{*}{ Ngamruengphong, S $2013^{(20)}$} & $\begin{array}{l}\text { M1-2-3 } \\
\text { SM1-2-3 }\end{array}$ & E 306 (NS)* & & 223 & $177(56)$ & $2485 y$ \\
\hline & EAC $98-09$ & $\begin{array}{l}\text { S } 1312(\mathrm{NS}) * \\
\text { E29 (EMR) }\end{array}$ & & $\begin{array}{c}1023 \\
19\end{array}$ & $\begin{array}{c}918(289) \\
17\end{array}$ & $10235 y$ \\
\hline Tian J, $2011^{(30)}$ & $\begin{array}{c}\text { SM1-2-3 } \\
\text { EAC } \\
95-10\end{array}$ & S39 (TT TH) & & 35 & 31 & \\
\hline \multirow[b]{2}{*}{ Pech O, $2011^{(22)}$} & M1-2-3 & E $76(\mathrm{NS}) *$ & 0 & 73 & 68 & $69-5 y$ \\
\hline & $\begin{array}{c}\text { EAC } \\
96-09\end{array}$ & S 38 (TT) & 1 & 35 & 35 & $38-5 y$ \\
\hline \multirow[b]{2}{*}{ Zehetner J, $2011^{(34)}$} & M1-2-3 & E 40 (EMR PDT) & $0(0)$ & $38(0)$ & 0 & \\
\hline & $\begin{array}{l}\text { EAC } \\
\text { 01/out }\end{array}$ & S 61 (TH TT MI VSR) & $0(16)$ & $57(0)$ & 7 & \\
\hline \multirow[b]{2}{*}{ Prasad GA, $2009^{(24)}$} & M1-2-3 & E 132 (EMR PDT) & $0(18)$ & & $109(1)$ & $105-5 y$ \\
\hline & $\begin{array}{l}\text { EAC } \\
98-07\end{array}$ & S 46 (TH TT) & $1(17)$ & & $43(1)$ & $45-5 y$ \\
\hline \multirow[b]{2}{*}{ Das A, $2008^{(6)}$} & $\begin{array}{l}\text { M1-2-3 } \\
\text { SM1-2-3 }\end{array}$ & E 99 (EMR PDT TA) & & 76 & 76 & \\
\hline & $\begin{array}{c}\text { EAC } \\
\text { ESCC } \\
98-03\end{array}$ & S 643 (NS)* & & 521 & 502 & \\
\hline \multirow[b]{2}{*}{ Schembre DB, $2008^{(25)}$} & M1-2-3 & E 62 (EMR APC PDT) & 1 & $55(0)$ & & \\
\hline & $\begin{array}{l}\text { EAC } \\
98-05\end{array}$ & $\mathrm{~S} 32(\mathrm{NS})^{*}$ & 0 & $30(0)$ & & \\
\hline \multirow{2}{*}{ Prasad GA, $2007^{(23)}$} & $\begin{array}{l}\text { M1 } \\
\text { EAC }\end{array}$ & E 129 (EMR PDT) & 0 & 122 & $118(0)$ & $110-5 y$ \\
\hline & $94-04$ & S 70 (TT TH) & $1(27)$ & 67 & $64(0)$ & $66-5 y$ \\
\hline \multirow{2}{*}{ Pacifico RJ, $2003^{(21)}$} & $\begin{array}{l}\text { M1-2-3 } \\
\text { SM1-2-3 }\end{array}$ & E 24 (EMR PDT) & $0(4)$ & & & $20-1 y$ \\
\hline & $\begin{array}{l}\text { EAC } \\
96-01\end{array}$ & S 64 (NS)* & $1(34)$ & & & $64-1 y$ \\
\hline \multirow[b]{2}{*}{ Fujita $\mathrm{H}, 2001^{(9)}$} & M1-2-3 & E 37 (EMR) & $0(2)$ & $26(0)$ & $22(0)$ & \\
\hline & $\begin{array}{l}\text { ESCC } \\
81-97\end{array}$ & $\mathrm{~S} 35$ (TT TH) & $5(24)$ & $26(0)$ & $24(0)$ & \\
\hline
\end{tabular}

M: mucosa; SM: submucosa; EAC: early adenocarcinoma; ESCC: squamous cell carcinoma; EMR: endoscopic mucosal resection; ESD: endoscopic submucosal dissection; TA: trans abdominal TH: trans hiatal; TT: trans thoracic; MI: minimally invasive; MAP: mortality associate to procedure; MoAP: morbidity associated to procedure; MAC: mortality associated to cancer; DFS: disease free survival; NS not specified. 


\section{Risk of bias within the studies}

The first approach to identify risk of bias was undertaken using the NEWCASTLE OTTAWA ${ }^{(10)}$ and Methodology Check List: Cohort studies SIGN ${ }^{(26)}$. Because all of the studies were retrospective cohorts from hospital care data networks, the rate was generally good.

\section{RESULTS OF THE INDIVIDUAL STUDIES AND THE SYNTHESIS OF THE RESULTS}

\section{3-year survival}

Risk Difference in 3-year survival for the endoscopy and surgery therapies.

Nine studies reported the 3-year survival, and the heterogeneity test indicated $\chi^{2}=9.35$ and $\mathrm{I}^{2}=14 \%$, which demonstrated a insignificant heterogeneity. The fixed-effects model was adopted, and the RD was -0.04 (95\% CI: -0.07 , -0.01) (Figure 2). An analysis of the pooled data revealed differences between the two therapies. There was a statistically significant increase in survival with the surgical therapy.

\section{5-year survival}

Risk Difference in 5-year survival for the endoscopy and surgery therapies.

Ten studies reported the 5-year survival, and the heterogeneity test indicated $\chi^{2}=14.08$ and $\mathrm{I}^{2}=36 \%$, which demonstrated a low heterogeneity. The fixed-effects model was adopted, and the RD was -0.10 (95\% CI: -0.12,-0.08) (Figure 3). An analysis of the pooled data revealed differences between the two therapies. There was a statistically significant increase in survival with surgical therapy.

\section{Disease-free survival after 5 years}

Risk Difference in disease-free survival after 5 years for the endoscopy and surgery therapies.

Five studies reported disease-free survival after 5 years, and the heterogeneity test indicated $\chi^{2}=29.28$ and $\mathrm{I}^{2}=86 \%$, which demonstrated a high heterogeneity. The fixed-effects model was adopted, and the RD was $-0.02(95 \% \mathrm{CI}:-0.06$, -0.02 ) (Figure 4). In the funnel plot analysis, the study by Ngamruengphong S. (2013) was identified as a source of

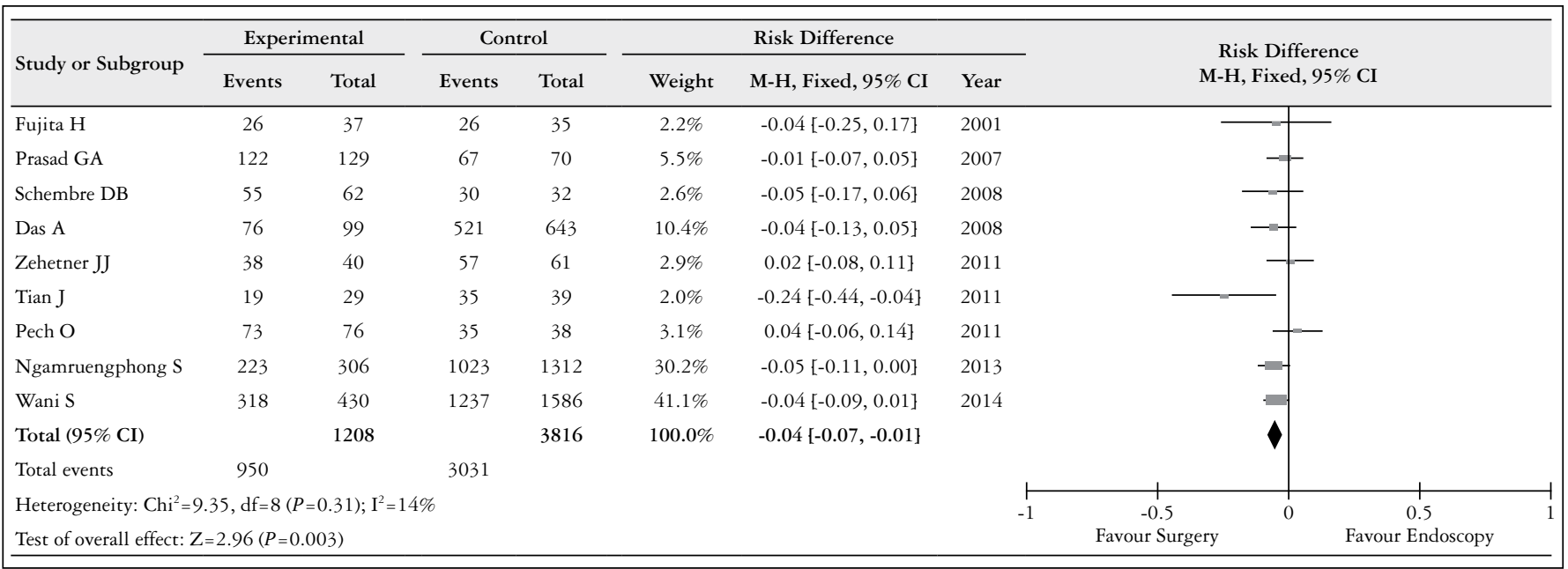

FIGURE 2. Risk difference in 3 year survival, for endoscopy and surgery therapies

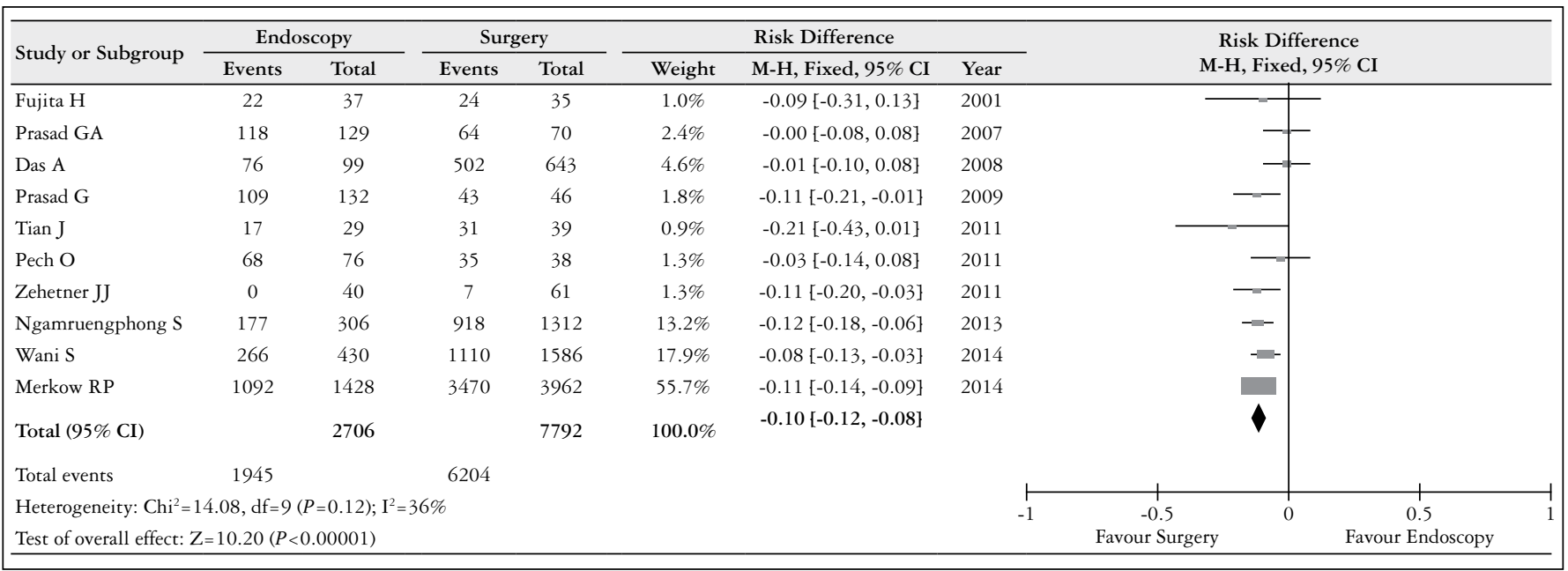

FIGURE 3. Risk difference in 5 year survival, for endoscopy an surgery therapies 


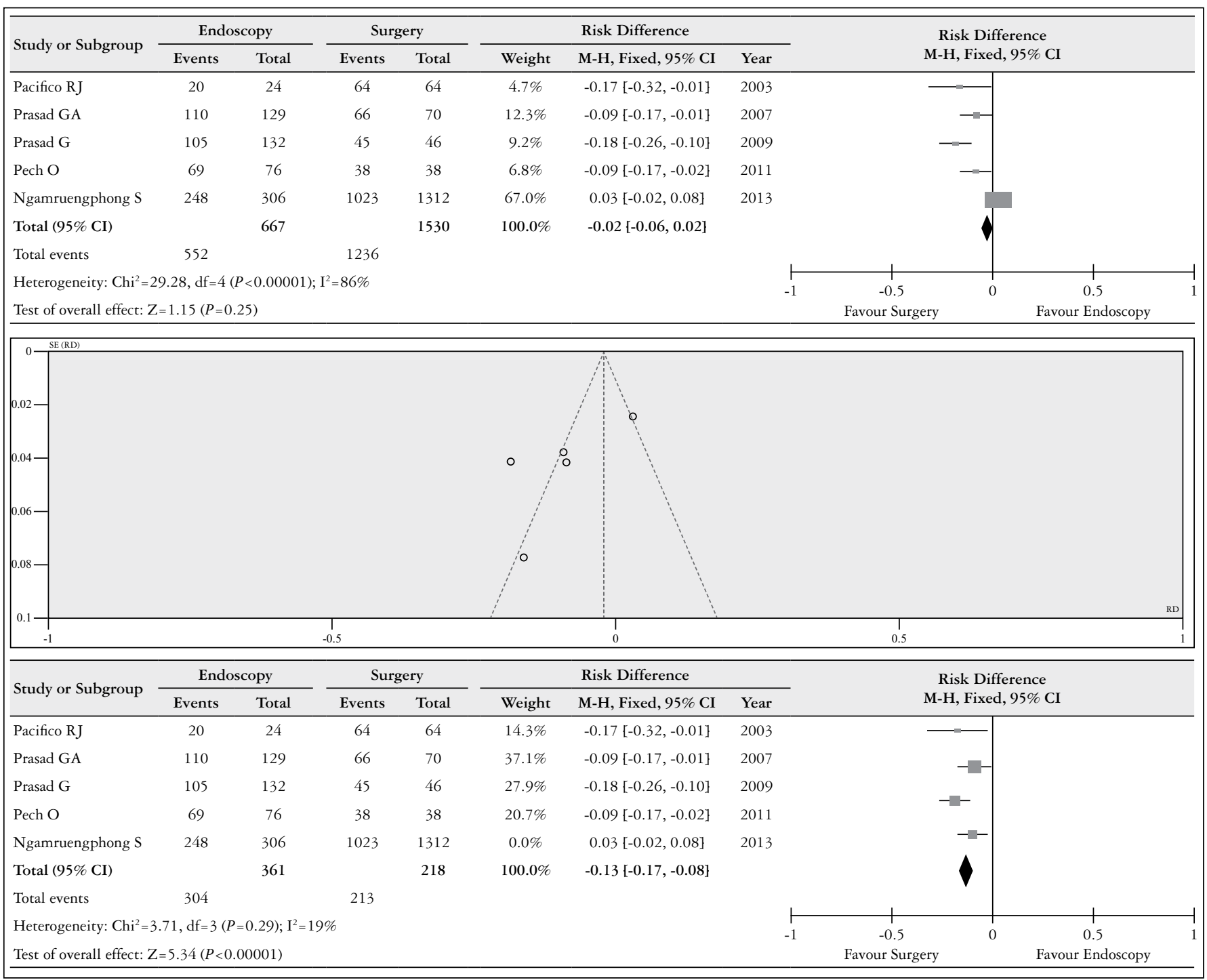

FIGURE 4. Risk difference in disease-free survival 5 years, for endoscopy and surgery therapies

heterogeneity; by consensus, the reviewers opted to withdraw this work. Four studies reported disease-free survival after 5 years, and the heterogeneity test indicated $\chi^{2}=3.71$ and $\mathrm{I}^{2}=19 \%$, which demonstrated a low level of heterogeneity. The fixedeffects model was adopted, and the RD was -0.13 (95\% CI: $-0.17,-0.08)$ (Figure 4$)$. An analysis of the pooled data revealed differences in the disease-free survival in the fifth year and showed better outcomes for the surgical therapy.

\section{Mortality associated with the procedure}

Risk Difference in the mortality associated with the procedure for the endoscopy and surgery therapies.

Eight studies reported mortality associated with the procedure, and the heterogeneity test indicated $\chi^{2}=8.85$ and $\mathrm{I}^{2}=21 \%$, which demonstrated an insignificant heterogeneity. The fixed-effects model was adopted, and the RD was -0.03 (95\% CI: -0.04,-0.02) (Figure 5). An analysis of the pooled data revealed differences between the two therapies. There was a statistically significant increase in mortality with the surgical therapy.

\section{Morbidity associated with the procedure}

Risk ratio in the morbidity associated with the procedure for the endoscopy and surgery therapies.

Four studies reported morbidity associated with the procedure, and the heterogeneity test indicated $\chi^{2}=6.38$ and $\mathrm{I}^{2}=53 \%$, which demonstrated a moderately high level of heterogeneity. The fixed-effects model was adopted, and the risk difference was -0.24 (95\% CI: -0.31, -0.16) (Figure 6). In the funnel plot analysis, we identified true heterogeneity, and the reviewers opted to perform a Risk Ratio analysis. Four studies reported morbidity associated with the procedure, and the analysis of the heterogeneity test indicated $\chi^{2}=2.61$ and $\mathrm{I}^{2}=0 \%$ low heterogeneity. Therefore, the fixed- 


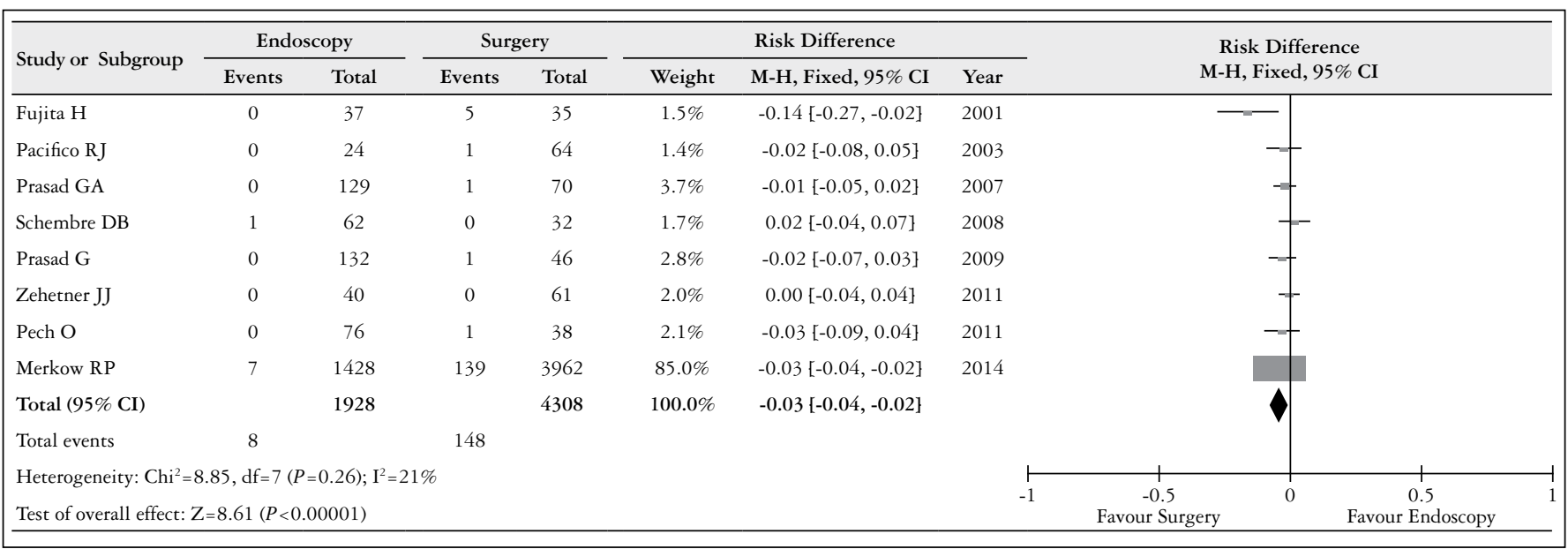

FIGURE 5. Risk difference in mortality associated with the procedure, for endoscopy and surgery therapies

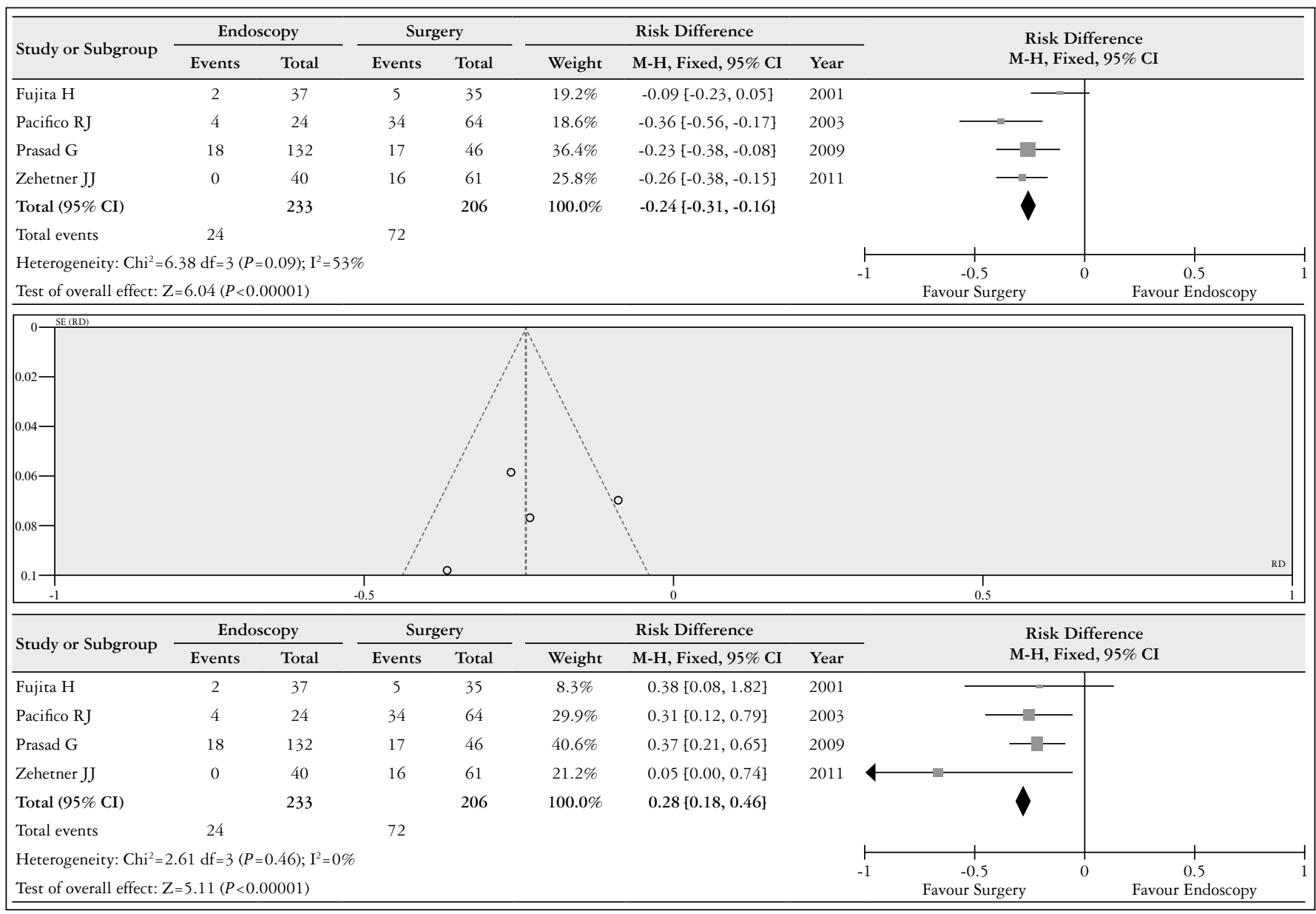

FIGURE 6. Risk ratio in morbidity associated with the procedure for endoscopy and surgery therapies

effects model was adopted, and the Risk Ratio was 0.28 (95\% CI: 0.18, 0.46) (Figure 6). An analysis of the pooled data revealed differences between the two therapies. There was a statistically significant increase in the morbidity associated with the surgical therapy procedure.

\section{Associated cancer mortality at 5 years}

Risk difference associated with cancer mortality at 5 years for the endoscopy and surgery therapies.

Five studies reported an associated cancer mortality at 5 years, and the heterogeneity test indicated $\chi^{2}=16.57$ and 
$\mathrm{I}^{2}=76 \%$, which demonstrated a high level of heterogeneity. Therefore, the fixed-effects model was adopted, and the RD was $-0.04(95 \%$ CI: $-0.06,-0.02, P=0.0004)$ (Figure 7 ). In the funnel plot analysis, the study by Prasad GA (2007) was identified as a source of heterogeneity. By consensus, the reviewers opted to withdraw this work. Four studies reported an associated cancer mortality at 5 years, and the heterogeneity test indicated $\chi^{2}=4.57$ and $\mathrm{I}^{2}=34 \%$, which demonstrated a low level of heterogeneity. Therefore, the fixed-effects model was adopted, and the RD was -0.04 (95\% CI: -0.07, -0.02) (Figure 7). An analysis of the pooled data revealed differences between the two therapies. There was a statistically significant increase associated with cancer mortality at 5 years in the surgical therapy procedure.

\section{Risk of bias across the studies}

In relation to the heterogeneity across the studies because both the endoscopic and surgical treatment protocols are different in various parts of the world, even more of the therapies described in each study were different. It is typical to identify combination therapies, including EMR, ESD, PDT, or ablative therapies, in one or more sessions. Additionally, the surgical techniques described are different in each study. There are predominantly open approaches (TT, TH) in the older studies and minimally invasive approaches in the recent studies (MI).

In the analysis of the disease-free survival at 5 years, in the funnel plot and $\mathrm{I}^{2}$ analysis identified publication bias in the study by Ngamruengphong S. (2013). After excluding this study, we observed a frank tendency to obtain better results

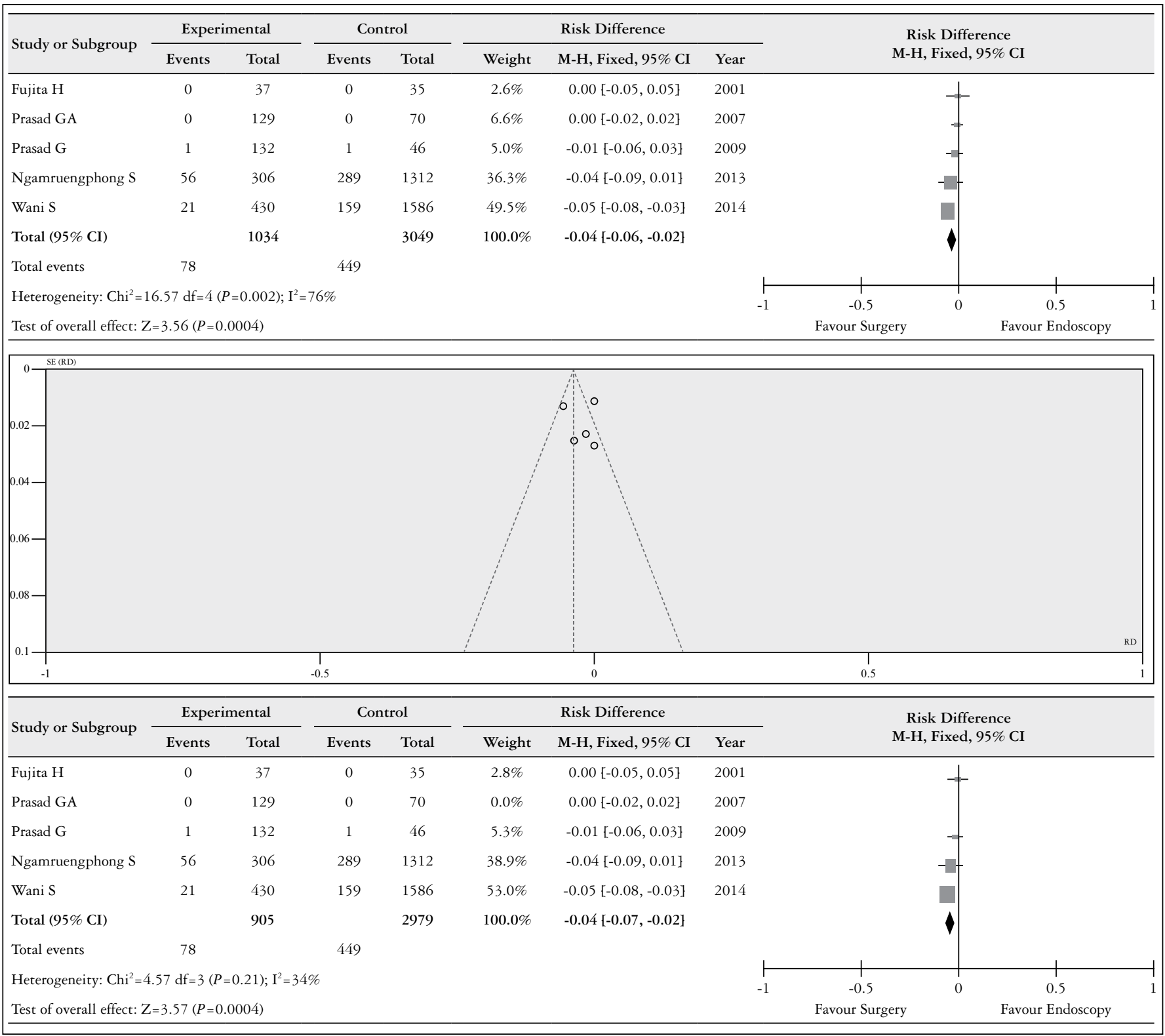

FIGURE 7. Risk difference in 5 years associated with câncer mortality for endoscopy and surgery therapies 
with surgical therapies regarding disease-free survival at 5 years. However, it is important to consider that the excluded study was the most recent study and that it also had the largest population sample; therefore, it had more population homogeneity. This finding could explain an improvement in the results of the disease-free survival in this study.

In the analysis associated cancer mortality at 5 years, the funnel plot and $\mathrm{I}^{2}$ analysis identified publication bias in the study by Prasad GA (2007). After excluding this study, we observed a frank tendency to obtain better results with endoscopy therapies and observed an increased mortality associated with cancer at 5 years with surgical therapies. More recent publications by the same author have shown more homogeneous results in relation to the other studies. Additionally, the bias was apparently given by population differences and may have been determined by the time lapse in which the study was conducted.

In the analysis of the morbidity associated with procedure, the funnel plot and $\mathrm{I}^{2}$ analysis identified true heterogeneity. By consensus, the reviewers opted to calculate the risk ratio with the low heterogeneity. This true heterogeneity is determined by population differences and mainly interventions.

\section{DISCUSSION}

Esophagectomy is the traditional treatment for early neoplasia in the esophagus. It is associated with a substantial morbidity and mortality rate, and endoscopic management is an important modality in these patients. We reviewed the literature to compare the two therapies.

In this analysis, we included early cancer of the esophagus, adenocarcinoma, and squamous cell cancer. We categorized these as M1, M2, M3, or SM1 according to the classification of Paris. Several endoscopic treatments were used in this analysis, including endoscopic mucosal resection (EMR), endoscopic submucosal dissection (ESD), photodynamic therapy (PDT), ratio frequency ablation (RFA), and argon plasma coagulation (APC). Several technical surgeries were also used in this analysis.

Esophagectomy is associated with more frequent major adverse events, which include bleeding, stenosis, anastomotic leakage, and others that cause extended hospitalization, high expenditure, and death. For the procedure-related morbidity and the procedure-related mortality, the differences were significant and favoured the endoscopy therapy.

The survival rates after 3 and 5 years were not similar and showed superiority in the surgical therapies over time. The difference in esophageal neoplasia-related death between the two treatments was significant, and the endoscopic therapies were superior in the analysis of the mortality associated with cancer, excluding the population selection bias. Although the recurrence rate is higher than the endoscopic therapies, as demonstrated by the analysis of the 5-year disease-free survivals, apparently disease control can be achieved with monitoring, identification, and effective treatment of these recurrences.

Several limitations of the present study need to be considered. All of the studies included in this analysis were retrospective cohorts. Additionally, the characteristics of the patients were not comparable in a number of the studies, and the patients treated endoscopically were older and had more medical comorbidities than those treated surgically, which may lead to a significant bias in the results. Several endotherapies, including ESD, EMR, PDT, RFA, and APC, were used. The treatment efficacy of each modality was different. The operation type of esophagectomy and the level of experience of the operators were also different in all studies.

\section{CONCLUSION}

This analysis is limited by the availability of only retrospective studies. In this analysis, the superiority of the surgical therapies on survival is evident, which increases over time and is apparently influenced by biases in the selection of the population. When this bias is removed, endoscopy exhibits superiority in controlling the mortality related to cancer, but it has a high rate of disease recurrence. With regard to the comorbidity and the mortality associated with the procedure, endoscopy is superior. Prospective, controlled trials with large sample sizes are required to confirm the results of the current analysis.

Systematic review registration number: CRD42014013170.

\section{Authors' contributions}

All authors contributed significantly to conception and design, acquisition of data, analysis and interpretation of data and drafting the article. 
Bustamante FAC, Hourneaux de Moura EG, Bernardo W, Sallum RAA, Ide E, Baba E. Terapias cirúrgicas versus endoscópicas para câncer precoce e displasia de alto grau no esôfago: uma revisão sistemática. Arq Gastroenterol. 2016,53(1):10-9.

RESUMO - Contexto - Cerca de $22 \%$ dos casos de câncer esofágico ocorrem como uma doença local e uma minoria é considerada lesão precoce, isto é, está limitada à mucosa ou submucosa. A ressecção endoscópica da mucosa, dissecção endoscópica da submucosa, a terapia fotodinâmica, a terapia laser e coagulação com plasma de argônio se desenvolveram como alternativas à ressecção cirúrgica para lesões precoces. Objetivo - O objetivo desta revisão sistemática é identificar estudos que comparam terapia endoscópica com terapia cirúrgica, quanto à sobrevivência, à sobrevivência livre de doença, à morbidade e a mortalidade associada ao procedimento e a mortalidade associada ao câncer. Fontes de dados - Revisão sistemática utilizando MEDLINE, COCHRANE, EMBASE, EBSCO, LILACS, Biblioteca da Universidade de São Paulo, BVS e ESCOPE. Seleção de estudo - Estudo randomizado controlado, ensaio clínico e estudo de coorte. Critérios - Estudos que comparam a sobrevivência, a sobrevivência livre de doença, a morbidade e a mortalidade associadas ao procedimento e mortalidade associada ao câncer na endoscópica e terapia cirúrgica para lesões precoces de câncer de esôfago. Extração de dados - Extração independente de artigos com dois autores usando campos de dados pré-definidos, incluindo indicadores de qualidade do estudo. Limitação - Somente estudos de coorte retrospectivos comparando endoscopia e a cirurgia foram recuperados. Resultados - As taxas de sobrevida após 3 e 5 anos foram diferentes e mostrou-se superioridade das terapias cirúrgicas em relação às endoscópicas ao longo do tempo. A endoscopia é superior no controle da mortalidade relacionada ao câncer com alta taxa de recorrência da doença. Em relação à morbidade e mortalidade associadas ao procedimento, a endoscopia é superior. Conclusão - Não há evidências de ensaios clínicos. Esta revisão sistemática mostrou superioridade na sobrevivência das terapias cirúrgicas. As terapias endoscópicas evidenciam superioridade no controle da mortalidade relacionada ao câncer com uma alta taxa de recorrência da doença. Além disso, a endoscopia correlaciona-se com menor morbidade e mortalidade associadas à intervenção. Ensaios controlados com grandes amostras são necessários para confirmar os resultados da análise atual.

DESCRITORES - Neoplasias esofágicas, cirurgia. Endoscopia gastrointestinal. Morbidade. Revisão.

\section{REFERENCES}

1. Alexandrou A Davis PA, Law S, Murthy S, Whooley BP. Squamous cell carcinoma and adenocarcinoma of the lower third of the esophagus and gastric cardia: similarities and differences. Dis Esophagus. 2002;15:290.

2. Bedenne L, Michel P, BouchéO, Milan C, Mariette C, Conroy T, et al. Chemoradiation followed by surgery compared with chemoradiation alone in squamous cancer of the esophagus: FFCD 9102. J Clin Oncol. 2007;25:1160.

3. Bennett C, Green S, Barr H, Bhandari P, Decaestecker J, Ragunath K, et al. Surgery versus radical endotherapies for early cancer and high grade dysplasia in Barrett's oesophagus. Cochrane Database Syst Rev. 2010:CD007334.

4. Bennett C, Green S, Decaestecker J, Almond M, Barr H, Bhandari P, et al. Surgery versus radical endotherapies for early cancer and high-grade dysplasia in Barrett's oesophagus. Cochrane Database Syst Rev. 2012:11:CD007334.

5. D'Amico TA. Outcomes after surgery for esophageal cancer. Gastrointest Cancer Res. 2007;1:188-96.

6. Das A, Singh V, Fleischer DE, Sharma VK. A comparison of endoscopic treatment and surgery in early esophageal cancer: an analysis of surveillance epidemiology and end results data. Am J Gastroenterol. 2008;103:1340-5.

7. Department Cochrane Informatics and Knowledge Management. Cochrane Informatics and Knowledge Manegement Department. 2014. [Internet]. [cited 2014 Oct 5]. Available from: http://tech.cochrane.org/revman/download.

8. Edge SB, Byrd DR, Compton CC, et al (Eds), American Joint Committee on Cancer Staging Manual, 7th. Springer, New York. 2010. p. 103.

9. Fujita H, Sueyoshi S, Yamana H, Shinozaki K, Toh U, Tanaka Y, Mine T, et al. Optimum treatment strategy for superficial esophageal cancer: endoscopic mucosal resection versus radical esophagectomy. World J Surg. 2001;25:424-31.

10. GA Wells, B Shea, D O'Connell, J Peterson, V Welch, M Losos, P Tugwell. The Newcastle-Ottawa Scale (NOS) for assessing the quality of nonrandomised studies in meta-analyses OTTAWA HOSPITAL 2014. [Internet]. [cited 2015 Aug 03]. Available from: http://www.ohri.ca/programs/clinical_epidemiology/oxford.asp.

11. Green S, Tawil A, Barr H, Bennett C, Bhandari P, Decaestecker J, et al. Surgery versus radical endotherapies for early cancer and high grade dysplasia in Barrett's oesophagus. Cochrane Database Syst Rev. 2009:CD007334.

12. Hirst J Smithers BM, Gotley DC, Thomas J, Barbour A. Defining cure for esophageal cancer: analysis of actual 5-year survivors following esophagectomy. Ann Surg Oncol. 2011;18:1766-74
13. Jadad AR, Moore RA, Carroll D, et al. Assessing the quality of reports of randomized clinical trials: is blinding necessary? Controlled Clin. Trials. 1996;17:1-12.

14. Kanamoto A, Yamaguchi H, Nakanishi Y, Tachimori Y, Kato H, Watanabe H. Clinicopathological study of multiple superficial oesophageal carcinoma. Br J Surg. 2000;87:1712.

15. Lightdale CJ. Esophageal cancer. American College of Gastroenterology. Am J Gastroenterol. 1999;94:20-9.

16. Mariette C, Finzi L, Piessen G, Van Seuningen I, Triboulet JP. Esophageal carcinoma: prognostic differences between squamous cell carcinoma and adenocarcinoma. World J Surg. 2005;29:39.

17. Menon D, Stafinski T, Wu H, Lau D, Wong C. Endoscopic treatments for Barrett's esophagus: a systematic review of safety and effectiveness compared to esophagectomy. BMC Gastroenterol. 2010;10:111.

18. Merkow RP, Bilimoria KY, Keswani RN, Chung J, Sherman KL, Knab LM, et al. Treatment trends, risk of lymph node metastasis, and outcomes for localized esophageal cancer. J Natl Cancer Inst. 2014;106.

19. Moher D Liberati A, Tetzlaff J, Altman DG. The PRISMA Group (2009). Preferred Reporting Items for Systematic Reviews and Meta-Analyses: The PRISMA Statement. 2009. [cited 2014 Mar 8]. [Internet]. Available from: http://www.prisma-statement.org/statement.htm.

20. Ngamruengphong S, Wolfsen HC, Wallace MB. Survival of patients with superficial esophageal adenocarcinoma after endoscopic treatment vs surgery. Clin Gastroenterol Hepatol. 2013;11:1424-9.

21. Pacifico RJ, Wang KK, Wongkeesong LM, Buttar NS, Lutzke LS. Combined endoscopic mucosal resection and photodynamic therapy versus esophagectomy for management of early adenocarcinoma in Barrett's esophagus. Clin Gastroenterol Hepatol. 2003;1:252-7.

22. Pech O, Bollschweiler E, Manner H, Leers J, Ell C, Hölscher AH. Comparison between endoscopic and surgical resection of mucosal esophageal adenocarcinoma in Barrett's esophagus at two high-volume centers. Ann Surg.2011;254:67-72.

23. Prasad GA, Wang KK, Buttar NS, Wongkeesong LM, Krishnadath KK, Nichols FC 3rd, Lutzke LS, Borkenhagen LS. Long-term survival following endoscopic and surgical treatment of high-grade dysplasia in Barrett's esophagus. Gastroenterology. 2007;132:1226-33.

24. Prasad GA, Wu TT, Wigle DA, Buttar NS, Wongkeesong LM, Dunagan KT, Endoscopic and surgical treatment of mucosal (T1a) esophageal adenocarcinoma in Barrett's esophagus. Gastroenterology. 2009;137:815-23. 
25. Schembre DB, Huang JL, Lin OS, Cantone N, Low DE. Treatment of Barrett's esophagus with early neoplasia: a comparison of endoscopic therapy and esophagectomy. [Journal] // Gastrointest Endosc. 2008;67:595-601.

26. Scotland Healtcare improvement. 2014. [Internet]. [cited 2015 Aug 4]. Available from: http://www.sign.ac.uk/guidelines/index.html.

27. Sgourakis G, Gockel I, Lang H. Endoscopic and surgical resection of T1a/T1b esophageal neoplasms: a systematic review. World J Gastroenterol. 2013;19:1424-37.

28. Shimada H, Nabeya Y, Matsubara H, Okazumi S, Shiratori T, Shimizu T, et al Prediction of lymph node status in patients with superficial esophageal carcinoma: analysis of 160 surgically resected cancers. Am J Surg. 2006;191:250.

29. Siewert JR, Ott K Are squamous and adenocarcinomas of the esophagus the same disease? Semin Radiat Oncol. 2007;17:38.

30. Tian J Prasad GA, Lutzke LS, Lewis JT, Wang KK. Outcomes of T1b esophageal adenocarcinoma patients. Gastrointest Endosc.2011;74:1201-6.
31. Wang GQ, Jiao GG, Chang FB, Fang WH, Song JX, Lu N, Lin DM, Xie YQ, Yang L Long-term results of operation for 420 patients with early squamous cell esophageal carcinoma discovered by screening. Ann Thorac Surg. 2004;77:1740.

32. Wani S, Drahos J, Cook MB, Rastogi A, Bansal A, Yen R, Sharma P, Das A Comparison of endoscopic therapies and surgical resection in patients with early esophageal cancer: a population-based study. Gastrointest Endosc. 2014;79:224-32.

33. York University of PROSPERO - International prospective register of systematic reviews. 2014. [2014 Aug 11]. [Internet] Available from: http://www.crd.york.ac.uk/ PROSPERO/display_record.asp?ID=CRD42014013170.

34. Zehetner J, DeMeester SR, Hagen JA, Ayazi S, Augustin F, Lipham JC, DeMeester TR. Endoscopic resection and ablation versus esophagectomy for high-grade dysplasia and intramucosal adenocarcinoma. J Thorac Cardiovasc Surg. 2011;141:39-47. 